\title{
Geographic Names and Domain Names
}

David Lindsay

Monash University

Review of Heather Ann Forrest, Protection of Geographic Names in International Law and Domain Name System Policy (2013, Wolters Kluwer) 339 pages including bibliography, tables and diagrams.

At the heart of many of the legal problems raised by the Internet is the fundamental tension between law (and legal rights), which are for the most part local, and the Internet, which transgresses legal borders. In many respects, the Domain Name System (DNS), which uses words (in which there may be legal rights) as part of a global addressing system, has been a laboratory for working through conflicts between local laws and global technologies. The conflicts are nowhere more apparent than in issues relating to the protection of geographic names - which are quintessentially connected to locations in the physical world - in the DNS. The rights of public authorities, including governments, over geographical names, including country names, was an important issue in ICANN's fraught New gTLD Program, which has opened up the DNS to a massive number of gTLDs. This book, which is the first major academic study of the legal protection of geographic names in the DNS, admirably fills a glaring gap in the scholarly literature, and provides a significant legal and historical knowledge base for the development and application of policy in this area.

ICANN's New gTLD Program, which may see the addition of over 1,400 TLDs (Top-Level Domains) to the DNS, provides the current focus for policy debates regarding geographical names, especially given that there were 66 applications for what are known as GeoTLDs as part of the program. These applications include applications for .tokyo and .berlin, which have already been delegated, as well as applications for .sydney, .melbourne and .nyc. As the author of the book, Heather Forrest, explains in the Introduction, the New gTLD Program was an opportunity for ICANN to clarify policy on a range of persistent issues, including the treatment of geographic names. After a comprehensive analysis of the relevant legal principles, however, by the end of the book the author concludes that ICANN's policy on the protection of geographic names has been based on inadequate assumptions about the law, and especially about the rights of States over geographic names under international law. Sadly, a lack of precise and accurate analysis of legal issues, including issues relating to legal 
process, sometimes seems to characterise developments led by technologists, including gTLD policy-making. The publication of this highly-accessible book, based on the author's Ph.D. thesis, means that ignorance of the law in this area should no longer be an excuse.

The book has three parts.

Part I, consisting of chapters 1 and 2, provides the building blocks for the subsequent parts by introducing the problems relating to rights in geographical names in the DNS, and explaining the DNS and its development. In chapter 1, Forrest sets out the context of the research problems addressed by the book by explaining why DNS disputes, to date, have focused on trademark rights in second and lower level domain names, but that the New gTLD Program has seen a shift in focus to rights in names in gTLDs. In the final version of the gTLD Applicant Guidebook (Version 2012-06-04), which sets out the rules for the New gTLD Program, there are two approaches to dealing with geographical names:

- Country or territory names are completely reserved from registration as new gTLDs; and

- Other geographic names - specifically including capital cities, cities, sub-national place names (county, province or state) and geographical indications (which are names that identify a product as originating from a geographic location) - can only be registered with the support or non-objection of relevant governments or public authorities.

As Forrest explains, the Guidebook simply assumed that governments (or other public authorities) have exclusive or superior rights in these geographic names, without any analysis of the position under international law. In chapter 2 , the book explains the evolution of the DNS, including the expansion of gTLDs, leading up to the decision to open up gTLDs with the New gTLD Program.

Part II of the book, which consists of chapters 3 and 4, explains the policy and legal frameworks for protecting rights in geographical names in the DNS (chapter 3) and under international law (chapter 4). Chapter 3 first sets the scene by explaining the development of systems for recognising trademark rights in domain names, including the Uniform Domain Name Dispute Resolution Policy (UDRP). As Forrest explains, rights in names may be protected either ex ante (such as by reserving names from use in the DNS) or ex post (by systems, such as the UDRP, which provide mechanisms for challenging registered domain names). The chapter includes an explanation of the controversy involving whether or not geographical names should be reserved from registration, which applies to second and lower level domain name registrations in new gTLDs pursuant to Specification 5 of ICANN's Registry Agreement. The problem with geographic names, as opposed to trademark law 
more generally, is that there is an absence of consistency between legal regimes in the protection accorded geographical names, including a lack of consistency in how geographical names are treated under national trademark laws. This explains why ex post dispute resolution mechanisms, such as the UDRP, have been confined to trademark rights, where they have been generally effective, but not extended to protect other rights, such as rights in geographical names.

Chapter 4 is an exposition of the legal framework for protecting rights in names under international law. It explains the sources of international law, the general principles of international law, and the growing role of non-state actors, including ICANN, in the developing international legal framework. As Forrest points out, an understanding of international law is essential to understanding the protection of rights in new gTLDs as the ICANN board adopted a recommendation that rights in strings must not infringe existing rights recognised under international law.

Part III of the book, consisting of chapters 5 to 9, explains and analyses the protection of geographic names under international law, with a view to evaluating the policies on the protection of geographic names in the DNS adopted and applied by ICANN. Chapter 5 explains the protection of geographic names under intellectual property law, especially trademark law. As the chapter explains, there are considerable difficulties in protecting geographic names as trademarks as such terms are generic or descriptive, not distinctive of a particular trader or business. With the exception of the special category of geographical indications, there are significant limits on the extent to which geographical names can be protected under intellectual property laws.

Chapter 6 is an exposition of rights in geographic names under international law, including whether States can prevent the registration of geographic names as trademarks and whether governments have inherent rights over country names as an incident of sovereignty. First, while Article 6ter of the Paris Convention on industrial property prohibits registration as a trademark of emblems of national significance, such as national flags, as Forrest explains, the prevailing view is that this does not prevent the registration of country names as trademarks. Second, the chapter examines the rights of States over country names as an incident of the principle of sovereignty, including analysis of a right to select a country name, a right to prevent the use of the same or similar name by other States, and a right to be referred to by a chosen name. As Forrest effectively points out, the position is extraordinarily complex, with considerable legal uncertainty. While sovereignty does not require a State to select and use a name, States have authority to do so if they so choose, and to control the use of that name within their sovereign territory. As a matter of international law, however, rights over country names are clearly not absolute. As is apparent from the complex dispute 
between Greece and the Former Yugoslav Republic of Macedonia (FYROM), a State's rights over a country name are not absolute but may be limited by obligations not to encroach on another State's sovereignty. There are, however, no clear legal rules for resolving one State's objections to the use of a country name by another State. Finally, although there is obviously a uniform international practice of referring to States by name, this is not based on clearly identifiable legal principles but rather on good international relations. Accordingly, there are no clear bases under international law for States to claim exclusive rights over geographic names, including over country names.

Chapter 7 deals with the protection of geographical indications, which are names used to denote the geographic origins of products, such as wines and spirits. The chapter examines the multiple legal frameworks applying to geographical indications, includng the TRIPS Agreement, which includes an obligation on member states to prevent the importation of goods that directly or indirectly use false geographic indications. The chapter concludes that the international protection of geographic indications, in the absence of trademark protection, has limited scope to prevent the use of a geographic name as a gTLD, as the protection relates to the use of names in association with goods, whereas TLDs are a service (for the registration of domain names under the TLD) with no direct connection to goods.

Chapter 8 considers the protection of geographic names under unfair competition laws, which essentially protects commercial names against misleading or deceptive business practices. This can include false representations of the source of a good or service. The chapter points out that there are serious difficulties in applying unfair competition law to gTLDs, including problems with categorising a potential registrant of a gTLD as a 'competitor' of a government or public authority associated with a geographic name. The analysis leads to the conclusion that the relevant articles of the Paris Convention (Arts. 10 and 10bis) do not require member States to prohibit the unauthorised registration of geographic names or geographical indications as gTLDs.

The final substantive chapter, Chapter 9, examines international human rights law, including rights to national identity, freedom of expression or cultural rights, as a potential basis for rights in geographic names. Acknowledging that there are links between human rights and geographic self-identification, the chapter concludes that the human rights to freedom of expression and to culture require recognition of a person's right to use a geographic name. This leads Forrest to the conclusion that the assertion by governments of exclusive rights over geographic names, including country names, in the DNS may be in breach of the fundamental human rights to freedom of expression and to culture.

As Forrest points out in her concluding chapter, which summarises the arguments set out in the book, DNS policy-making should be based on an accurate analysis of the legal protection 
of rights in names, and not merely assumptions. On the basis of the analysis of international law presented in the book, Forrest concludes that there is no compelling foundation, as a matter of international law, for States to assert exclusive rights over geographic names, including country names. In fact, insofar as it is possible to reach conclusions on the application of international law to the DNS, international human rights law (which protects individuals and not States) suggest that assertions of exclusivity by governments may be in breach of human rights. The uncertain legal basis for ICANN's policies of restricting the registration of geographic names as gTLDs lead Forrest to predict that there may be greater attempts to protect geographic names as trademarks under domestic intellectual property laws, such as has been pioneered in Switzerland.

The lack of academic attention given to the complex legal issues relating to domain name law and policy is an ongoing source of surprise, especially given the potential for the DNS to raise novel and highly significant legal issues. One possible explanation for the relative scarcity of authoritative research in the area is the high barriers to entry, arising from the dense thickets of technical and bureaucratic jargon that characterises DNS policy-making. Despite the unavoidable use of acronyms, this book is very clearly written, providing accessible introductions to complex legal issues. The author, who is a lecturer at the Australian Catholic University, displays a rare combination of skill and rigour in collecting and synthesising a wealth of source material, both technical and legal.

The central arguments, some of which are substantially original, are clearly presented, with helpful summaries at the end of each substantive chapter. This is an admirable achievement in an area that is as replete with inconsistencies and ambiguities, and subject to such diverse legal regimes, as the protection of geographic names under international law. By clearly elucidating legal issues that have apparently been overlooked by ICANN in developing its New gTLD Program, including the suggestive analysis of the implications of international human rights law for rights in geographic names, the book performs an important public service. The book, moreover, advances legal understanding of both private and public legal rights in names by means of a detailed case study of the regimes that apply to the protection of geographic names in the DNS.

Finally, the book highlights the importance of independent scrutiny of claims that are made by governments - in this case, the claims to exclusivity over geographic names by ICANN's Governmental Advisory Committee (GAC) - which all too often fail to withstand sustained critical analysis. Although it is understandable that there will be some lapses in an endeavour as complex and demanding as ICANN's New gTLD Program, the fragility of the international DNS governance arrangements require continual vigilance, especially in scutinising the claims made by powerful stakeholders, including those represented in the GAC. If 
appropriate internal safeguards are not applied, the ICANN multi-stakeholder model will continue to be threatened, including by competing models that may potentially be more centralised and less consultative.

Cite this article as: Lindsay, David. 2014. 'Geographic Names and Domain Names'. Australian J ournal of Telecommunications and the Digital Economy 2 (1): 29.1-29.6. DOI: http://doi.org/10.7790/ajtde.v2n1.29. Available from: http://telsoc.org/journal 